\title{
The Effects of Input Enhancement Techniques on ESP Learners' Microgenetic Development of Conjunction Production
}

\author{
Hadi Salehi (Corresponding author) \\ English Department, Najafabad Branch, Islamic Azad University, Najafabad, Iran \\ Email: hadisalehi1358@yahoo.com \\ Ali Shahpari \\ English Department, Najafabad Branch, Islamic Azad University, Najafabad, Iran
}

Aliasghar Ahmadishokouh

Payam Noor University, Tehran, Iran

Received: 20/05/2020

Accepted: 23/08/2020

Published: 01/09/2020

Volume: 1 Issue: 1

How to cite this paper: Salehi, H., Shahpari, A., \& Ahmadishokouh, A. (2020). The Effects of Input Enhancement Techniques on ESP Learners' Microgenetic Development of Conjunction Production. Journal of Practical Studies in Education 1(1), 6-14

DOI: https://doi.org/10.46809/jpse.v1i1.8

Copyright $@ 2020$ by author(s) and Global Talent Academy Ltd. This work is licensed under the Creative Commons Attribution International License (CC BY 4.0).

http://creativecommons.org/licenses/by/4.0/

(c) $($ )

\begin{abstract}
Microgenetic design or microgenetic method is a scientific method in which the same setting is studied repeatedly in order to observe possible changes in details. Reviewing the current literature, one can conclude that microgenetic methods have positive effects of learning in general and language learning in particular. The main objective of the current study was to investigate the possible effects of implementing input enhancement techniques using microgenetic methods, on Iranian ESP learners' conjunction production. To this end, a number of 40 Iranian ESP learners were participated in the study. During the four-week period of the current study, the participants received the instructions and treatment, two sessions a week and each session lasted for an hour. After administering the pre-test before the instruction, using input enhancement techniques, a number of the conjunctions were presented and taught to the learners in the first session. The data were collected after instructional sessions during the first, third, fifth, and seventh weeks through paragraphs focusing on conjunction production written by the participants. The results indicated that, in the course of time, input enhancement techniques using microgenetic methods, significantly affect Iranian ESP learners' conjunction production.
\end{abstract}

Keywords: Microgenetic Method, Input Enhancement Techniques, ESP Learners, Conjunction Recognition

\section{Introduction}

Smith and Truscott (2014) believe that, the term "input enhancement", was originally coined to cover any type of tailored input, that is, whether the manipulation in question amounted to simply making certain grammatical or phonological features of the input visibly or acoustically more salient, or whether much more elaborate and explicit techniques were used such as pointing out and explaining L2 properties, rules and principles. They argue that the term seems to have been used by researchers almost exclusively in connection with the first, perceptual type of enhancement. 
There is no doubt that input enhancement is a broadly documented concept in language teaching and learning, but the findings of some studies revealed to be controversial in many areas. For instance, a study by Curry and Hewing (2003) reported positive effects for the acquisition of question formation whereas Thompson (2013) found no effects for visual input enhancement. Lee and Huang (2008) did a meta-analysis of visual input enhancement and grammar learning and concluded that the results of research to date were inconclusive. Smith and Truscott (2014) pointed out that, what should be clear is that any account of input enhancement needs to be tied up to some coherent view of memory and activation. Simply put, when we manipulate learners' linguistic environment, we need to work with some coherent account of what is going on inside, i.e. in their minds. It seems that focusing on the developmental changes during learning language skills in general and writing skill, the focus of this study, in particular, is the area that have some potentials to shed lights on what is going on in the language learner s mind, which didn't get enough attention among the language scholars.

The process of change represents a main and central issue for the study of development. Basic and applied researchers in developmental science have aimed their research work at answering several key questions related to the problem of change. How does change occur? What mechanisms produce change? What conditions are likely to promote the emergence of change in development? (Lavelli, et.al, 2008). Microgenetic development, which roots in the Vygotsky's sociocultural learning theory, is a specific method for studying change in abilities, knowledge, and understanding during short time spans, through dense observations, and over a relatively long period of time (Ahmadian, 2013).

Ahmadian (2013) further argued that Microgenetic method is identified with three essential properties which distinguish it from conventional longitudinal methods: a) observations span a period from the beginning of a process of change until a relatively stable state; (b) within this period the density of observations is high relative to the rate and the period of change; and (c) observations are analyzed intensively via trial-by-trial analyses which zero in on inferring the processes that gave rise to qualitative or quantitative changes. He also argues for potentiality of microgenetic method in improving language teaching. He believes that the rationale behind this argument is twofold:

(1) microgenetic method accelerates the change processes by providing participants with frequent provisions of instruction/stimulus in a way that would not occur in normal experience and this would place us in a position to argue that the accelerated process of change is to a very large extent a function of the intensive treatment given to learners ; and (2) since microgenetic method yields detailed information about both inter- and intra-individual variability, we can ascertain, with some degree of certainty, when, where, and how participants lose stability or exhibit backward transition in their developmental behavior. (p.65)

Concurrent with these discussions about the need for incorporating microgenetic development in teaching language skills, this study is an attempt to investigate the possible effects of implementing input enhancement techniques using microgenetic methods, on Iranian ESP learners' conjunction production. In order to fulfill this need the following questions are raised:

1-What microgenetic development do ESP learners' conjunction production undergo, when using input enhancement techniques?

2-Do input enhancement techniques using microgenetic method have any significant effects on Iranian ESP learners' conjunction production?

It was also hypothesized that input enhancement techniques using microgenetic method have no significant effects on Iranian ESP learners' conjunction production.

\section{Literature Review}

A key question in instructed SLA research and practice is how learner attention can be drawn to linguistic features during L2 learning activities. While this issue has been the subject of much research over the past two decades, L2 researchers have only more recently begun to explore ways in which learner attention can be directed to L2 constructions during activities entailing various modalities, such as audio and pictorial input. More successful word recognition also enables learners to identify new lexical items in the input with greater ease, promoting attention to and learning of new vocabulary (Naghdipour, 2016).

Only part of the input to which learners have access gets processed and subsequently learned, and attention is considered a principal cognitive mechanism determining what part of the input is selected for further processing (Sarani \& Izadi, 2016). According to Leow and Martin (2017), these findings suggest that, when the readers' primary goal is to extract meaning from written input, textual enhancement alone does not have the capacity to trigger sufficient depth of processing for learning to occur. Leow and Martin also observe, however, that developmental benefits for textual enhancement were more likely to be found in studies when textual enhancement was used together with other attention-getting tools (e.g., feedback, explicit instruction), probably due to the higher level of processing achieved through the combination of techniques.

Cintrón-Valentín and Ellis (2015) investigated the learning of L2 Latin verbal morphology by L1 English speakers. L1 influenced reliance on adverbial cues blocks learners' attention to more important verbal morphology. The study found that highlighting morphological cues through color coding in computer-delivered input increased attention to this salient feature and helped learners' overcome the adverbial block to improve learning. This suggests more explicit grammar teaching is not necessary. 
Malone (2016) investigated the effects of vocabulary learning through reading using input enhancement techniques. He has shown that uninstructive input enhancement works, and that controlled laboratory studies should now be undertaken. Long (2017) acknowledges that SLA researchers" emphasis on "incidental and implicit L2 learning in adults" is "still a minority position in the world of language teaching". He argues that explicit teaching should not take the form of a grammatical syllabus, but rather focus on form, or un-intrusive input enhancement. The importance of input has been in the field of second or foreign language acquisition. However, kinds of input and ways of its presentation are among the controversial issues in L2 classroom research (Jafarigohar \& Jalali, 2014).

As we globalize - or "glocalize" - language-learners seem set to continue exploring new and novel ways to customize language. Literary production is one way the local becomes global, and the canon of "English" literatures is loaded with numerous L2 writers (Disney, 2014). Hence, the ability of second language students to express themselves in writing is at the heart of what it means to be literate in a language and students are often evaluated by their control of it.

Researchers have investigated potentially influential factors for L2 writing development both cross sectionally and longitudinally (Oliveira \& Silva, 2016). They believed that in terms of cross sectionally, the construct of L2 writing ability has usually been measured by L2 writing quality. In contrast, longitudinal studies, although scarce in number, can allow us to establish more confidently a causal relationship between various factors and L2 writing development.

As Thompson (2013) puts it, over the past two decades, there have been severe discussion on the two major approaches towards writing, namely product - based approach and process- based approach. He continues to say that the product-based writing, which is the traditional approach towards writing, focuses on the results of writing expression, or the written product, rather than the process. In contrast, a recent approach to writing, the process-based writing approach aims to arrange the writing process according to constructivist teaching theory and with the cognitive assistance of a teacher (ibid). Process approaches do not repudiate all interest in the product. The aim is to achieve the best product possible. What differentiate a process focused approach from the product centered one that the outcome of writing, the product, is not preconceived. (Kamrul \& Mohd, 2010).

As Andrade and Evans (2013) put it, given that many EFL contexts place a high premium on traditional pedagogical practices and approaches to teaching writing, exposing the shortcomings of such practices could inform English language teachers and educators about the importance of advocating for more realistic curricula and deploying more effective instructional approaches to better accommodate the learning needs of students in writing classes. In another line of research, (Naghdipour, 2016) contended that L2 studies has continued to absorb ideas from different fields: from linguistics (formal and functional), applied linguistics, psychology (behavioral and cognitive), rhetoric, composition studies, education, anthropology, sociology, the philosophy of science, and others. In contrast, Majchrzak(2018) states that, in the past decades, the focus of many foreign language (FL) writing studies has been more on the pedagogical aspects than on the psycholinguistic aspects of FL writing. One of the core questions of cognitively oriented writing research is, of course: What's involved in writing? Or what would the 'blueprint of the writer' look like? (Manchon, 2009). It seems that the process of change during which learners demonstrate their gradual abilities in writing is not fully considered.

The process of change represents a main, central issue for the study of development. Basic and applied researchers in developmental science have aimed their research work at answering several key questions related to the problem of change. How does change occur? What mechanisms produce change? What conditions are likely to promote the emergence of change in development? (Lavelli, et.al, 2008). They argued that despite recent advances in both theoretical perspectives and methods focused on change processes that have brought considerable progress in the research field, the main problem appears to come from the difficulty of devising and implementing appropriate methods for studying change while it is occurring (e.g. microgetetic development), instead of comparing pre- and post-change behavioral patterns. One of the methods of investigating the process of change during learning in general and language learning in particular, which caught the attentions of researchers is microgenetic development.

\subsection{Microgenetic Development}

Encyclopedia of the Sciences of Learning defines microgenetic method as "an approach used in cognitive developmental research which allows obtaining detailed data about changes in a particular competence at the moment the change is actually taking place. This approach is characterized by three key properties: (a) observations encompass the entire period of change, starting before the change begins and continuing until the competence has reached a relatively stable state, (b) the density of observations is high relative to the rate of change of the competence under study, and (c) observations are analyzed intensively on an individual and trial-by-trial basis as to understand the process that gives rise to both qualitative and quantitative aspects of change. The second property is especially important. Densely sampling changes while they are occurring provides the temporal resolution needed to understand the process of change." In the same way, Kim and Ritter (2016) observe that microgenetic approach provides an understanding of how a local performance in a task affects. Lavelli et.al (2008) underscored two principal premises underlie the use of microgenetic designs. The first one is that focusing on the microgenetic details of children's behavior in particular contexts made it possible for gaining the type of fine-grained information that is necessary to understand change processes. Another premise is that observing and understanding changes at the micro-level of real time is fundamental to understanding changes at the macro-level of developmental time.

Microgenetic design differs from cross-sectional and longitudinal designs in that, in the former the researcher can see the process of change, but in the latter the focus is on the product.The justification for using microgenetic development is that traditional cross sectional and longitudinal designs only provide before and after snapshots but tells us very little about the 
processes that produced a given change, while the microgenetic method places more demands on time and resources its potential for rich data is high.(Shabani,2018)

Lavelli, et.al (2008) describe the four key characteristics of microgenetic designs. The first one is that individuals are observed through a period of developmental change. The second characteristic is that observations are conducted before, during, and after a period during which rapid change in a particular domain occurs. The third feature is that there is an elevated density of observations within the transition period. The forth one is that observed behaviors are intensively analyzed, both qualitatively and quantitatively, with the goal of identifying the processes that give rise to the developmental change.

Microgenetic designs in language teaching root in Vygotsky sociocultural theory. Within this sociocultural perspective, a microgenetic analysis in language teaching deals with the moment-to-moment changes observed during interaction in language classes, which is used as a dynamic assessment of a child's "zone of proximal development (Lavelli, et.al, 2008)

2.2. Studies on Micogenetic Development in Language Teaching And Learning

Ahmadian (2013 ) in his study concluded that Microgenetic method is very difficult to conduct, but given the highquality and detailed data that this research method yields and in light of the increasing ease with which to analyze complex data hoped for a future in which microgenetic studies have proliferated in the field of SLA. In their study, Gass and Macky (2016) demonstrated that novice teacherse agency and externalization of their thoughts in a supportive and interactive environment can result in their development.

In a study on The Role of Consciousness-Raising Tasks on EFL Learners' Microgenetic Development of Request Pragmatic Knowledge, Tajeddin and Hosseinpour (2014) contended that in the course of time, the participants stopped using direct request strategies and employed conventionally indirect strategies more frequently in situations involving high-status interlocutors and high-imposition requests. Sarani and Izadi (2016) believe that to have a complete picture of learners' abilities, actual scores are not self-sufficient. Mediated scores, using microgenetic efforts are vital to diagnose learners' areas of difficulties and to promote learners' receptive vocabulary knowledge. They also indicated that DA is promising in presenting a fine-grained diagnosis of learners' receptive vocabulary development while also suggesting information related to future teaching and learning.

Gutierreze (2008) in a study on collaborative activity in a Spanish as a foreign language classroom, concluded that microgenetic analysis of the data allowed us to gain further understanding of collaborative activity and of the importance of language as a mediational tool to co-construct meaning and learning opportunities. Fogal (2019) in a microgenetic analysis of seven adult Japanese learners of English in a three-week writing course designed to help students develop their authorial voices revealed learning dimensions that were (i) wide in breadth, (ii) isomorphic in their rate, (iii) triggered by repeated tasks in a teaching-and-learning cycle facilitated by stylistic analyses, (iv) variegated across learners, and (v) erratic and nonlinear.

\section{Method}

\subsection{Participants}

The participants of the current study were 40 male ESP learners studying Electronics in one of the military universities in Tehran. The participants aged from 18 to 20, were randomly grouped in two equal-in-number, experimental classes (each group consists of 20 members).

\subsection{Instruments}

\subsubsection{Conjunction Test}

This test was administered as the pre-test (to evaluate the related knowledge of the participants on conjunctions) and the post-test (to evaluate the influence of treatment and instructions among the participants on learning and producing conjunctions) of the study. It was also designed as a picture-cued production test type (Izumi, Bigelow, Fujiwara, \& Fearnow, 1999; cited in Torki, 2017). Moreover, a picture in military context which implied to contain a story to be narrated by the participants of the study was intentionally chosen by the researchers. In addition to the picture, a list of 22 conjunctions inserted in a table was provided to the participants, too. Then, the learners were required to write as many paragraphs as possible about the picture through applying provided conjunctions in the table. The conjunctions should be used both meaningfully and structurally appropriate in the text. Moreover, an adequate amount of encouragement was offered to the participants to use more conjunctions.

In fact, the more conjunctions used, the higher scores were assigned for them. Actually, the chief target and main purpose of this test was the number of appropriately and acceptably used conjunctions in the text and the amount of meaningful parts of the text. For the post-test after an interval of two weeks, the same procedure was performed on the same test. It means that both administered tests (pre- and post-tests) were equal in content.

\subsection{Treatment Materials}

During the first, third, fifth, and seventh sessions of the instruction, the required data were collected. Right after receiving the instruction in these sessions, the participants were provided with an extracted piece of electronic warfare news from military websites such as "Military.com, Defensenews.com, Breakingdefense.com, and Fifthdomain.com". As a matter of fact, in each odd session, one text was presented for the learners. All the instructional materials (four pieces of news) were in line with the purpose of the research. 


\subsection{Data Collection Procedure}

\subsubsection{Instruction and Collection}

During the four-week period of the current study, the participants received the instructions and treatment, two sessions a week and each session lasted for one hour. After administering the pre-test before the instruction, the whole number of the conjunctions were presented and taught to the learners in the first session. It was performed through the use of input enhancement techniques. To this end, some sentences or short paragraphs including blanks were presented for the learners with some key words underlined, highlighted, italicized, bold-faced, or CAPITALIZED, as the clues to find the most appropriate conjunction. On this basis, the learners could rewrite the sentences or fill in the blanks with the acceptable and suitable conjunctions. This procedure continued for both odd and even sessions during the eight sessions.

However, in order to measure the microgenetic developmental changes, in odd sessions or treatment sessions, after readministering the whole number of conjunctions, a piece of news extracted from previously mentioned military websites was provided for the participants. Once, the whole meaning and structure of the text was approximately clear for them, the participants were required to rewrite the text through the use of appropriate conjunctions. This procedure was done through the rest of treatment sessions.

3.4.2. Scoring

Due to the subjectivity of testing and scoring the writing skill, the researchers came to this end to assign the scoring of the tests based on the table 3.1 (Torki, 2017).

Table 3.1. Assigned 20 Scores for the Picture-Cued Test Type

\begin{tabular}{|c|c|c|}
\hline Activity & $\begin{array}{l}\text { Point per } \\
\text { activity }\end{array}$ & $\begin{array}{c}\text { Overall } \\
\text { point }\end{array}$ \\
\hline Writing just some grammatical sentences & 3 & \\
\hline Writing one paragraph with no conjunctions & 4 & \\
\hline $\begin{array}{l}\text { Writing one meaningful paragraph which includes one conjunction that is } \\
\text { not appropriately used }\end{array}$ & 6 & \\
\hline $\begin{array}{l}\text { Writing one meaningful paragraph which includes one appropriately used } \\
\text { conjunction and another repeated conjunction. }\end{array}$ & 8 & \\
\hline $\begin{array}{l}\text { Writing one meaningful paragraph which includes two or more } \\
\text { appropriately used conjunction }\end{array}$ & 11 & 20 \\
\hline $\begin{array}{l}\text { Writing one meaningful paragraph with two appropriately used } \\
\text { conjunctions and some repeated conjunctions }\end{array}$ & 13 & \\
\hline $\begin{array}{l}\text { Writing two meaningful paragraphs which include three appropriately used } \\
\text { conjunctions }\end{array}$ & 15 & \\
\hline $\begin{array}{l}\text { Writing two meaningful paragraphs which include up to five conjunctions } \\
\text { that are appropriately used }\end{array}$ & 18 & \\
\hline $\begin{array}{l}\text { Writing three meaningful paragraphs with six appropriately used } \\
\text { conjunctions. Some of the conjunctions are repeated. }\end{array}$ & 20 & \\
\hline
\end{tabular}

\subsection{Data Analysis}

The current study included one intact class which was tested on six conditions as follows: one pre-test, four post-tests (as microgenetic development changes), and one delayed post-test. In order to find the differences of the scores during six tests, repeated measures ANOVA and post-hoc comparison tests were utilized to examine the participants' development over time.

\section{Results}

The first research question of the study was aimed at investigating the microgenetic development of the ESP learners' conjunction production, when using input enhancement techniques. In order to in deal with this research question, the ESP learners' conjunction production Changes over the course of instruction was illustrated in the table 4.1. 
Table 4.1: The frequency of conjunctions used in the different stages of written texts produced by the participants

\begin{tabular}{|c|c|c|c|c|c|c|c|c|c|c|c|c|c|c|c|c|c|c|c|c|c|c|}
\hline & 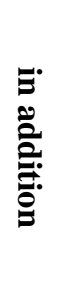 & 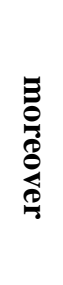 & 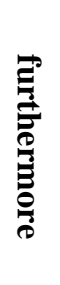 & 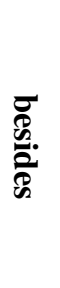 & 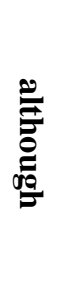 & 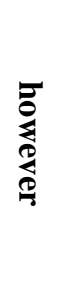 & $\stackrel{\Xi}{\Xi}$ & 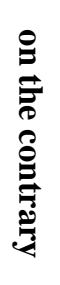 & 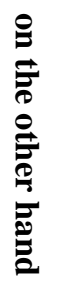 & 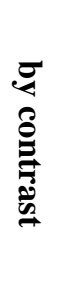 & 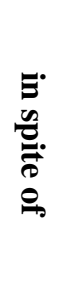 & $\frac{\stackrel{0}{8}}{\stackrel{0}{0}}$ & $\begin{array}{l}\overrightarrow{\vec{\sigma}} \\
\frac{0}{0} \\
\stackrel{0}{0} \\
\stackrel{0}{0}\end{array}$ & \% & 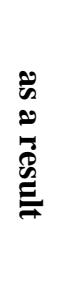 & 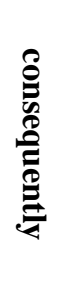 & 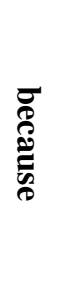 & 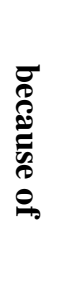 & 气̊. & $\begin{array}{l}\stackrel{2}{0} \\
\overrightarrow{0}\end{array}$ & $\begin{array}{c}\text { E. } \\
0 \\
0 \\
0 \\
0 \\
0 \\
0 \\
0\end{array}$ & 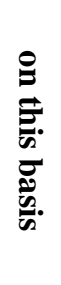 \\
\hline Pretest & 0 & 0 & 0 & 0 & 1 & 0 & $\begin{array}{l}1 \\
7\end{array}$ & 0 & 0 & 0 & 0 & 0 & 0 & $\begin{array}{l}1 \\
5\end{array}$ & 0 & 0 & $\begin{array}{l}1 \\
3\end{array}$ & 0 & 0 & 0 & 0 & 0 \\
\hline Post 1 & 4 & 2 & 1 & 0 & 2 & 4 & 5 & 1 & 2 & 0 & 1 & 0 & 1 & 6 & 3 & 1 & 4 & 3 & 0 & 1 & 3 & 1 \\
\hline Post 2 & 3 & 6 & 1 & 1 & 2 & 4 & 2 & 2 & 2 & 2 & 1 & 1 & 3 & 3 & 8 & 2 & 4 & 2 & 2 & 1 & 3 & 2 \\
\hline Post 3 & 3 & 4 & 4 & 3 & 3 & 3 & 1 & 4 & 3 & 2 & 2 & 2 & 2 & 2 & 5 & 4 & 2 & 3 & 5 & 4 & 5 & 3 \\
\hline Post 4 & 4 & 5 & 5 & 4 & 5 & 6 & 2 & 3 & 3 & 3 & 3 & 2 & 6 & 2 & 6 & 7 & 4 & 5 & 4 & 5 & 6 & 5 \\
\hline Delayed & 4 & 5 & 4 & 3 & 2 & 3 & 3 & 2 & 2 & 2 & 3 & 3 & 4 & 4 & 4 & 6 & 5 & 6 & 5 & 4 & 6 & 4 \\
\hline
\end{tabular}

As shown in the table 4.1, in pretest the frequency of just four conjunctions used by the participants is as followed: (although: one time, but: 17 times, so: 15 times, and because: 13 times). It clearly indicates that these conjunctions are among the most common and popular conjunctions among ESP learners. However, in the posttest stages, other conjunctions were used frequently by the participants in their texts. For example, some conjunctions like "in addition", "moreover", however", and "in order to" which were not used in the pretest, they were used in posttest stages. Furthermore, the conjunctions which had the highest frequency in pretest stage, were not used in posttest stages so much. It indicates that the treatment had been successful in learning and using conjunctions.

The purpose of the second research question was to probe whether input enhancement techniques using microgenetic method have any significant effects on Iranian ESP learners' conjunction production. As displayed in Table 4.2, the overall mean scores of the participants throughout the four tests show a gradual improvement in conjunction recognition.

Table 4.2 Descriptive statistics of participants' mean scores for their four tests

\begin{tabular}{lrrr}
\hline & \multicolumn{3}{c}{ Descriptive Statistics } \\
& Mean & Std. Deviation & $\mathrm{N}$ \\
\hline PRETEST & 11.60 & 1.15 & 40 \\
FIRSTPOST & 13.90 & 1.53 & 40 \\
SECPOST & 15.37 & 1.70 & 40 \\
THIRDPOST & 17.42 & 1.67 & 40 \\
FORTHPOST & 17.27 & 1.69 & 40 \\
DELAYPOST & 16.02 & 1.80 & 40 \\
\hline
\end{tabular}

To see if the difference is statistically significant, the results of the repeated measures ANOVA was reported as follows.

Table 4.3 Mauchly's Test of Sphericity ${ }^{\text {a }}$ for meeting the sphericity assumption Measure: MEASURE_1

\begin{tabular}{|c|c|c|c|c|c|c|c|}
\hline \multirow{2}{*}{$\begin{array}{l}\text { Within Subjects } \\
\text { Effect }\end{array}$} & \multirow{2}{*}{$\begin{array}{l}\text { Mauchly's } \\
\text { W }\end{array}$} & \multirow{2}{*}{$\begin{array}{l}\text { Approx. Chi- } \\
\text { Square }\end{array}$} & \multirow[t]{2}{*}{$\mathrm{df}$} & \multirow[t]{2}{*}{ Sig. } & \multicolumn{3}{|c|}{ Epsilon $^{b}$} \\
\hline & & & & & $\begin{array}{l}\text { Greenhouse- } \\
\text { Geisser }\end{array}$ & $\begin{array}{l}\text { Huynh- } \\
\text { Feldt }\end{array}$ & $\begin{array}{l}\text { Lower- } \\
\text { bound }\end{array}$ \\
\hline factor 1 & .131 & 75.409 & 14 & .701 & .523 & .564 & .200 \\
\hline
\end{tabular}

The Mauchly's Test of Sphericity table 4.3 gives a Mauchly's W test statistic of $0.701, \mathrm{DF}=14 ; \mathrm{p}>0.05$. We can therefore conclude that the sphericity assumption has been met and we can use the output from the univariate model without correction. 
Table 4.4,Tests of Within-Subjects Effects for analyzing participants' performance in the four tests Measure: MEASURE_1

\begin{tabular}{llrrrrr}
\hline Source & & $\begin{array}{c}\text { Type III Sum of } \\
\text { Squares }\end{array}$ & df & Mean Square & F & Sig. \\
& Sphericity Assumed & 983.633 & 5 & 196.727 & 298.845 & .000 \\
\multirow{5}{*}{ factor1 } & Greenhouse-Geisser & 983.633 & 2.614 & 376.303 & 298.845 & .000 \\
& Huynh-Feldt & 983.633 & 2.819 & 348.980 & 298.845 & .000 \\
& Lower-bound & 983.633 & 1.000 & 983.633 & 298.845 & .000 \\
& Sphericity Assumed & 128.367 & 195 & .658 & & \\
Error(factor1) & Greenhouse-Geisser & 128.367 & 101.944 & 1.259 & \\
& Huynh-Feldt & 128.367 & 109.925 & 1.168 & \\
& Lower-bound & 128.367 & 39.000 & 3.291 & \\
\hline
\end{tabular}

The important rows in table 4.4 have been highlighted above and are the Sphericity Assumed rows.F $(5,195)=298.845$, $p$ $<0.01$. As $\mathrm{p}<0.01$, this indicates that we have found a significant difference in the performance on our participants in the four tests. Therefore, the null hypothesize of the study is strongly rejected. And we can safely argue that input enhancement techniques using microgenetic method have significant effects on Iranian ESP learners' conjunction production. But we do not, however, know where the differences lie, and therefore must consult the post hoc test for this information.The Pairwise Comparisons table (table 4.5) gives us a multiple comparison for the means of all paired combinations of the three repeated measures conditions.

Table 4.5, Pairwise Comparisons: multiple comparison for the means of all paired combinations of the three repeated measures conditions.

\begin{tabular}{|c|c|c|c|c|c|c|}
\hline & & & Measure: $\mathrm{N}$ & JRE_1 & & \\
\hline (I) & $(\mathrm{J})$ & Mean & Std. & Sig. $^{\mathrm{b}}$ & 95\% Confiden & Interval for \\
\hline factor1 & & Difference (I-J) & Error & & Difference $^{\mathrm{b}}$ & \\
\hline & & & & & Lower Bound & Upper Bound \\
\hline & 2 & $-2.300^{*}$ & .135 & .000 & -2.722 & -1.878 \\
\hline & 3 & $-3.775^{*}$ & .184 & .000 & -4.351 & -3.199 \\
\hline 1 & 4 & $-5.825^{*}$ & .196 & .000 & -6.437 & -5.213 \\
\hline & 5 & $-5.675^{*}$ & .222 & .000 & -6.369 & -4.981 \\
\hline & 6 & $-4.425^{*}$ & .223 & .000 & -5.123 & -3.727 \\
\hline & 3 & $-1.475^{*}$ & .134 & .000 & -1.894 & -1.056 \\
\hline 2 & 4 & $-3.525^{*}$ & .193 & .000 & -4.128 & -2.922 \\
\hline & 5 & $-3.375^{*}$ & .228 & .000 & -4.089 & -2.661 \\
\hline & 6 & $-2.125^{*}$ & .227 & .000 & -2.835 & -1.415 \\
\hline & 4 & $-2.050^{*}$ & .152 & .000 & -2.524 & -1.576 \\
\hline 3 & 5 & $-1.900^{*}$ & .185 & .000 & -2.480 & -1.320 \\
\hline & 6 & $-.650^{*}$ & .198 & .032 & -1.269 & -.031 \\
\hline & 5 & .150 & .122 & 1.000 & -.230 & .530 \\
\hline 4 & 6 & $1.400^{*}$ & .151 & .000 & .928 & 1.872 \\
\hline 5 & 6 & $1.250^{*}$ & .106 & .000 & .919 & 1.581 \\
\hline
\end{tabular}

The results of the post-hoc comparison tests indicate that the progress from pretest $(\mathrm{M}=11.60)$ to first post test $(\mathrm{M}=$ 13.90) was statistically significant $(\mathrm{MD}=2.30, \mathrm{p}=<.05)$. The post-hoc test results also show that the progress from the first post test $(M=13.90)$ to the second post test $(M=15.37)$ was statistically significant $(M D=1.47, p=<.05)$. It also came to light that the progress from test $3(\mathrm{M}=15.37)$ to the third post test $(\mathrm{M}=17.42)$ was statistically significant $(\mathrm{MD}=2.05, \mathrm{p}=<$ $.05)$. It is also shown that the progress from the third post test $(\mathrm{M}=17.42)$ to the forth post test $(\mathrm{M}=17.27)$ was not statistically significant $(\mathrm{MD}=.15, \mathrm{p}=>.05)$. Finally, it was concluded that the progress from the forth post test $(\mathrm{M}=17.27)$ to the delayed post test $(\mathrm{M}=16.02)$ was statistically significant $(\mathrm{MD}=1.25, \mathrm{p}=<.05)$.

\section{Discussion}

The research study presented here was focused on the investigation of a group of ESP learners' microgenetic development and the changes and developments that their conjunction recognition underwent at given points in time during the instruction through input enhancement techniques. The results of the study indicated that implementing input enhancement techniques 
using microgenetic methods, has significantly affected the Iranian ESP learners' conjunction production.They employed some conjunctions during the third and forth sessions that they had not used in the first or second data collection sessions. These findings highlight the significant role of input enhancement techniques in English language teaching. These results bring once again to the fore the benefits of instruction especially in EFL context and suggest that instruction facilitates noticing, raises learners' awareness of English conjunction recognition knowledge, and thus helps in converting input to intake (Schmidt, 1995.in Tajodin .\& Mohammad Hosseinpur,(2014)). This finding supports Ebadi and Askaran (2017) which concluded that microgenetic method had a significant effect on the development in the participants' cognition and their movement toward further self-regulation. In line with the finding of this study, Shabani (2018) concluded that microgenetic instruction could diagnose quite vividly the learners' sources of writing difficulties and help promote the abilities which are in the state of maturation.

\section{Conclusion}

Scrutinizing the participants' microgenetic development in conjunction production was the main purpose of the study. The overall results of the study highlighted the students' conjunction production development over time. For example, some conjunctions like "in addition", "moreover", however", and "in order to" which were not used in the pretest, they were used in posttest stages. Furthermore, the conjunctions which had the highest frequency in pretest stage, were not used in posttest stages so much. As displayed previously, all the participants were successful in producing proper conjunctions. Practically, the findings of the present study can be considered an enlightenment within the teaching pedagogy and assessment practice, having far-reaching implications for both. For classroom based teaching and assessment, in particular, the study can illuminate the path through which writing teachers can assist their learners to have a higher performance and simultaneously develop in writing ability. All in all, it should be reiterated that microgenetic- based instruction can bring about many benefits for classroom praxis.

The first limiting factor is the sampling method. The participants of this study were selected through availability sampling; the results would be different if other sampling procedures were utilized. Another limitation is the small sample size included in this study which may have influenced the results of some statistical tests. This is a normal restriction in studies that are carried out in real educational settings where research is part of the participants' regular schedule. Finally, the findings are also directly related to the quality of mediations utilized by the researchers of this study only; different mediators might come up with different results with the same participants.

\section{References}

Ahmadian, M.J. (2013).The use of microgenetic method in SLA research. Applied Research on English Language, 2(1).

Andrade, M. S. \& Evans, N. W. (2013). Principles and practices for response in second language writing. London, UK: Routledge Taylor \& Francis group.

Cintrón-Valentín, M. and Ellis, N. (2015) Exploring the interface: explicit focus-on- form instruction and learned attentional biases in 12 Latin. Language Learning, 37(2), 197-235. Retrieved from https://doi.org/10.1017/s0272263115000029

Curry, M. \& Hewing, A. (2003). Approaches teaching academic writing: A toolkit for higher education. London, UK: Routledge.

Disney, D. (2014).Exploring second language creative writing. Amsterdam: John Benjamins Publishing Company.

Ebadi, S. \& Asakereh, A. (2017). Developing EFL learners' speaking skills through dynamic assessment: A case of a beginner and an advanced learner. Cogent Education, 4(1). Retrieved from https://doi.org/10.1080/2331186X.2017.1419796

Fogal, G. (2019). Tracking microgenetic changes in authorial voice development from a complexity theory perspective. Applied Linguistics. 40(3), 432-455

Gass, S. M., \& Mackey, A. (2016). Stimulated recall methodology in applied linguistics and L2 research. New York: Routledge.

Gutierreze, A.G. (2008). Microgenesis, method and object: A study of collaborative activity in a spanish as a foreign language classroom. Applied Linguistics, 29(1), 120-148.

Jafarigohar, M. \& Jalali, M. (2014). The effects of processing instruction, consciousness-raising tasks, and textual input enhancement on intake and acquisition of the English causative structures. Iranian Journal of Applied Linguistics (IJAL), 17(1), 93-118.

Kamrul, H. \& Mohd, M. (2010). Approaches to writing in EFL/ESL context: Balancing product and process in writing class at tertiary level. Journal of NELTA, 15 (1-2), 77-88.

Kim, J. W \& Ritter, F. E. (2016). Microgenetic analysis of learning a task: Its implications to cognitive modeling. D. Reitter\& F. E. Ritter (Eds.), Proceedings of the 14th International Conference on Cognitive Modeling (ICCM 2016)( pp.21-26).University Park, United States: Penn State. ISBN (Electronic): 9780998508207

Lavelli, M \& Andréa P. F \& Hui-Chin, H \& Messinger, D \& Fogel, A.(2008). Using microgenetic designs to study change processes.In D. G. Teti (Ed.), Handbook of Research Methods in Developmental Psychology. Hoboken, New Jersey: Blackwell Publishers. 
Lee, M \& Haung, A. (2008). Promoting grammatical development through textually enhanced captions: An eye-tracking study. The modern language journal, 102 (3), 557-577.

Leow, R. P., \& Martin, A. (2017). Enhancing the input to promote salience of the L2: A critical overview. In S. Gass, P. Spinner, \& J. Behney (Eds.), Salience in SLA (pp. 167-186). New York: Routledge.

Long, M. (2017). Instructed second language acquisition (ISLA): geopolitics, methodological issues, and some major research questions. ISLA, 1(1): 7-44.

Luwel, K. (2012). Microgenetic Method. In: Seel N.M. (Eds) Encyclopedia of the Sciences of Learning. Springer, Boston, MA. Retrieved from https://doi.org/10.1007/978-1-4419-1428-6_1754

Majchrzak, O. (2018). Learner identity and learner beliefs in EFL writing, second language learning and teaching. New York: Springer International Publishing.

Malone, J. (2016) Incidental vocabulary learning in SLA: effects of frequency and aural enhancement (Qualifying Paper. PhD in SLA Program). College Park: University of Maryland

Manchón, R. (2009). Writing in foreign language contexts learning, teaching, and research. Bristol: Multilingual Matters, St Nicholas House

Naghdipour, B. (2016). Incorporating formative assessment in Iranian EFL writing: a case study. The Curriculum Journal, 28(2), 283-299. doi:10.1080/09585176.2016.1206479

Oliveira, L .C \& Silva, T. (2016). Second language writing in elementary classrooms instructional issues, content-area writing and teacher education. New York: Palgrave Macmillan.

Sarani, A. \& Izadi, M. (2016). Diagnosing L2 Receptive Vocabulary Development Using Dynamic Assessment: A Microgenetic Study. Journal of Teaching Language Skills (JTLS), 35(2),161-189.

Shabani, K. (2018). Group dynamic assessment of L2 learners' writing abilities. Iranian Journal of Language Teaching Research, 6(1), 129-149.

Smith, A. \&.Truscott, T. (2014) .L2 writing pedagogy in EFL contexts: An exploration of salient practices in teaching and learning, The Journal of Asia TEFL, 6 (3), 351-373.

Tajodin, Z. \& Mohammad Hosseinpur, R. (2014). The role of consciousness-raising tasks on EFL learners' microgenetic development of request pragmatic knowledge. Iranian Journal of Applied Linguistics (IJAL), 17 (1), $147-187$.

Thompson, I. (2013). The mediation of learning in the zone of proximal development through a co-constructed writing activity. Research in the Teaching of English, 47(3), 247-276.

Torki, R. (2017). The effect of noticing the gap on learning conjunctions (Unpublished Master's thesis). University of Qom, Iran. 